\title{
Non-Fluoridated Remineralising Agents - A Review of Literature
}

\author{
Akriti Batra ${ }^{1}$, Vabitha Shetty ${ }^{2}$, \\ 1,2, Department of Paediatric \& Preventive Dentistry, A.B. Shetty Memorial Institute of Dental Sciences \\ (NITTE Deemed to Be University), Derlakatte, Mangalore, Karnataka, India.
}

\section{ABSTRACT}

Dental caries is not merely a continuous and one-way process of demineralisation of the mineral phase, but repeated episodes of demineralisations and remineralisation. The remineralisation process is a natural repair mechanism to restore the minerals again, in ionic forms, to the hydroxyapatite (HAP) crystal lattice. It occurs under nearneutral physiological $\mathrm{pH}$ conditions whereby calcium and phosphate mineral ions are redeposited within the caries lesion from saliva and plaque fluid resulting in the formation of newer HAP crystals, which are larger and more resistant to acid dissolution. An insight into the caries process's multifactorial aetiopathogenesis has resulted in a paradigm shift towards minimally invasive dentistry. This era of personalised care using the medical model for caries management assimilates the signs of examining, diagnosing, intercepting, and managing dental caries at a microscopic level. Fluoride mediated salivary remineralisation system is considered the cornerstone of non-invasive approach for managing non-cavitated carious lesions. However, the effect of fluoride was found to be limited to the outer surface of the tooth, and it was observed that fluoride does not influence the modifiable factors in dental caries such as the biofilm. Hence, fluoride does not reduce the cariogenic challenge especially for high-risk individuals. Due to this gap in the conventional fluoride therapies, non-fluoridated remineralising systems have emerged, which interact with the tooth by delivering calcium and phosphorous ions, modifying the biofilm and neutralising the organic acids. This review re-examines the philosophy behind non-fluoridated remineralisation, their mode of action, availability in the market and evidence-based studies of the most promising advancements in remineralisation approaches.

\section{KEY WORDS}

Caries, Minimally Invasive Dentistry, Remineralisation, Non-Fluoridated Remineralising Systems
Corresponding Author:

Dr. Vabitha Shetty,

Capitol Apartments, Flat No. 702,

Mangalore, Karnataka, India.

E-mail: docvabitha29@gmail.com

DOI: $10.14260 /$ jemds/2021/136

How to Cite This Article:

Batra A, Shetty V. Non-fluoridated remineralising agents - a review of literature. J Evolution Med Dent Sci 2021;10(09):638-644, DOI: $10.14260 /$ jemds/2021/136

Submission 09-10-2020,

Peer Review 22-12-2020

Acceptance 29-12-2020,

Published 01-03-2021.

Copyright (C) 2021 Akriti Batra et al. This is an open access article distributed under Creative Commons Attribution License [Attribution 4.0 International (CC BY 4.0)] 


\section{BACKGROUND}

Dental caries is the most prevalent oral disease which affects the teeth and is characterised by the destruction of calcified tissues, eventually leading to excruciating pain and functional limitations. Caries is not merely an uninterrupted and one-way demineralisation process, but a recurring event that comprises periods of demineralisation and remineralisation. ${ }^{1}$ The process of demineralisation begins at the atomic level of the enamel or dentine's crystal surface and continues to occur unless ceased, ultimately leading to cavitation. ${ }^{2}$ It entails mineral loss at the leading edge of lesion, under enamel, involving the transfer of acidic calcium and phosphate supersaturating plaque fluid. Addition of these minerals also occurs from the leading front of the lesion towards plaque. ${ }^{3}$

Remineralisation is natural restoration process of the hydroxyapatite (HAP) crystal lattice with the lost minerals, in their ionic forms. ${ }^{4}$ This takes place at neutral $\mathrm{pH}$ situations where tooth minerals in ionic forms are deposited again into carious site resulting in the deposition of newly formed apatite crystals. The newly formed crystals are larger in size and exhibit greater solubility under an acidic attack. ${ }^{5}$

A conventional restorative approach for eliminating carious lesions was developed a century ago; however, a superior understanding of caries progress has resulted in a paradigm shift to minimally invasive dentistry. Modern dentistry aims to inactivate non cavitated lesions using noninvasive strategies such as modification of the biofilm, dietary modification and utilisation of remineralising agents; and micro-invasive strategies such as application of sealants and caries infiltration methods attempting to avert progression of disease and to refine the strength, aesthetics and function of teeth.

\section{REMINERALISATION SYSTEMS}

\section{Natural Remineralisation Solely is Inadequate}

The remineralisation capability of saliva is undeniable. It delivers tooth minerals in ionic form in their assimilability state to develop calcified tissues as well as their sustainability throughout life. ${ }^{6}$ At neutral $\mathrm{pH}$, saliva is in a state of supersaturation with tooth mineral ions, thereby guaranteeing these minerals are available for mineral deficient lesions. ${ }^{2}$ Nevertheless, long-term studies that assessed the progression of white spot lesions (WSL) observed a reduction in size of WSL, but they mainly seemed to be unchanged even after two years. ${ }^{7}$ Hence, net salivary remineralisation is timeconsuming, ${ }^{8}$ with a propensity for the addition of minerals on the surface only owing to the lesser gradient of ionic concentration from saliva into the carious lesion. ${ }^{9}$

\section{Fluoride Based Remineralisation}

Since the 1980's customary fluoride-based remineralisation was regarded as the benchmark for rendering carious lesions inactive, which was established by the several evidence-based literature. ${ }^{10}$, This considerable decrease in caries experience in developed nations from the twentieth century was mainly accredited to extensive utilisation of fluoride products. However, fluoride-mediated salivary remineralisation is limited distinctly to the external $30 \mu \mathrm{m}$ of the tooth.
This surface-only remineralisation, which usually occurs because of substantial topical fluoride concentration, increases the occurrence of hidden caries ("fluoride syndrome") among various age groups. ${ }^{11}$ Fluoride is very efficacious on smooth-surface caries; its impact seems restricted to pit and fissure caries. ${ }^{12}$. Pit and fissure caries represent the majority of caries occurrence in advanced countries presently availing the benefits of fluoride, warranting the use of alternative agents.

The unfolding epidemiological data shows a worrying pattern, with caries occurrence leveling out or even expanding in some populations, despite of using fluoride dentifrices routinely. ${ }^{13} \mathrm{~A}$ dose-related association of reducing caries occurrence with increasing the concentration of dentifrice was noted. ${ }^{14}$ The documented delay in caries reduction rates has been accredited to its multifactorial aetiology. Firstly, diets worldwide are evolving to encompass more processed and sugar-laden foods, thereby restricting fluoride's repair potential. ${ }^{15}$ Secondly, fluoride does not impact oral biofilms, which is a principal modifiable component in the caries process, which tends to lessen the cariogenic challenge.

Fluoride and salivary homeostatic components are frequently sufficient in remineralising early lesions during normal physiological concentrations. Yet salivary mediated fluoride remineralisation is not enough, especially in highly cariogenic oral environments. Thirdly, the present-day classification of fluoride as a chemical neuro-toxicant has also raised concerns regarding the welfare of the general public when it comes to using a high concentration of fluoride products. ${ }^{16}$

There is an increasing concern that children these days are presented with different sources of fluoride. This, in turn, possibly increases their risk of developing dental fluorosis. ${ }^{17}$ Fluoride's 'halo' effect accounts for this sudden increase in the occurrence of permanent tooth mottling. ${ }^{18}$ The World Health Organization (WHO) has advocated the necessity of evaluating the total fluoride exposure before initiating other supplemental fluoride strategies for caries prevention. ${ }^{19}$

Due to this small narrow "dose gap" between the benefit of caries reduction $\mathrm{v} / \mathrm{s}$ side effects of fluoride, regulatory specialists have restricted the concentration of fluoride in toothpaste to approximately $1000-1500$ ppm. However, children below six years of age, the dose is even lower for early lesions' remineralisation. ${ }^{19}$ New age remineralisation innovations are needed to complement fluoride and reduce the gap in remineralising efficacy of fluoride.

\section{Requirement for Non-Fluoride Strategies 20}

1. Effect of fluoride seems to be more extensive on smooth-surface caries, but it displays limited efficacy on pit and fissure caries.

2. To avoid the potential for adverse effects (e.g., fluorosis) a high-fluoride strategy cannot be followed.

3. Fluoride toxicity increases with inadequate nutrition.

4. In spite of proving its remineralising efficacy, there is a wide gap when it comes to complete rehabilitation.

5. The anti-fluoride lobby, which is staging pressure, posed certain legal implications when it comes to using fluoride. 
6. The availability of fluoride products is still questionable in certain nations.

\section{NON-FLUORIDE ENAMEL REMINERALISING SYSTEMS}

\section{Classification and Mechanisms}

There is a worldwide agreement that the fundamental philosophy of managing modern-day caries is to "conserve the tooth structure and restore only when essential. New remineralisation strategies either renew the body of the lesion or dispense ions, which favors subsurface mineralisation. In addition to which it significantly reduces the requirement of traditional restorations and preserve tooth structure. The majority of promising remineralising strategies are briefly summarised in Table 1.19,20

- Biomimetic Regeneration Systems.

- Agents that deliver calcium and phosphate ions to the tooth surface.

- Agents that modify the biofilm.

- Agents that neutralise organic acids.

- Antimicrobials and antibiotics.

\begin{tabular}{|c|c|}
\hline Technology & Commercial Product \\
\hline Biomimetic systems & $\begin{array}{c}\text { Curodont Repair / Curodont Protect } \\
\text { Apagard toothpaste / Desensin oral } \\
\text { rinse }\end{array}$ \\
\hline \multicolumn{2}{|l|}{$\begin{array}{l}\text { Agents that deliver calcium and phosphate } \\
\text { ions to tooth surface }\end{array}$} \\
\hline $\begin{array}{l}\text { 1. Casein phosphopeptide stabilised calcium } \\
\text { phosphate (rcaldentT, CPP-ACP) }\end{array}$ & $\begin{array}{c}\text { Tooth mousse / MI paste cremes, } \\
\text { Trident white sugar-free gum, MI } \\
\text { paste ONE toothpaste }\end{array}$ \\
\hline $\begin{array}{l}\text { 2. Unstabilised amorphous calcium phosphate } \\
\text { (ACP, enamelon TM) }\end{array}$ & $\begin{array}{c}\text { Enamelon toothpaste, Enamel Pro } \\
\text { varnish }\end{array}$ \\
\hline $\begin{array}{l}\text { 3. Bioactive glass containing calcium sodium } \\
\text { phosphosilcate (Nova Min TM) }\end{array}$ & NovaMin toothpaste \\
\hline 4. Functionalised $\beta$-tricalcium phosphate & $\begin{array}{l}\text { Clinpro toothpaste, Clinpro white } \\
\text { varnish }\end{array}$ \\
\hline \multicolumn{2}{|l|}{ Agents that modify the biofilm } \\
\hline 1. Arginine bicarbonate and urea & Colgate - Palmolive (1.5 \% arginine) \\
\hline 2.0zone gas & HealOzone, OZOTOP \\
\hline \multicolumn{2}{|l|}{ Agents that neutralise organic acids } \\
\hline \multicolumn{2}{|l|}{ 1. Calcium glycerophosphate } \\
\hline \multicolumn{2}{|l|}{ 2. Calcium phytate } \\
\hline \multicolumn{2}{|l|}{$\begin{array}{l}\text { 3. Calcium lactate } \\
\text { Anti-plaque agents }\end{array}$} \\
\hline \multicolumn{2}{|l|}{ Anti-plaque agents } \\
\hline $\begin{array}{l}\text { 1. Antimicrobials and antibiotics chlorhexidine } \\
\text { triclosan }\end{array}$ & Listerine \\
\hline 2. Xylitol & $\begin{array}{l}\text { Xylitol chewing gums, Xylitol gummy } \\
\text { bear snacks, Xylitol syrups, Xylitol } \\
\text { toothpaste, Xylitol mouth rinse }\end{array}$ \\
\hline \multicolumn{2}{|l|}{ 3. Metallic salts } \\
\hline & \\
\hline
\end{tabular}

\section{REVIEW OF NON-FLUORIDATED REMINERALISING AGENTS}

Main type of calcium that is seen in cow milk and blood is calcium phosphate. It is a significant constituent of hydroxyapatite (HA) crystals, which is why the concentrations of calcium and phosphate in saliva and plaque influence the demineralisation and remineralisation of teeth. Optimal enamel recalcification rate is achieved with a $\mathrm{Ca} / \mathrm{P}$ proportion of 0.6 when they are supersaturated at equal degrees. The Ca / $\mathrm{P}$ ratio is approximately 0.3 in plaque fluid. ${ }^{21}$ Hence, there is a need for additional calcium supply, which can augment the remineralisation of enamel. Calcium and phosphate-based topical remineralising agents are classified based into three categories: $^{2}$

\section{Functionalised $\beta$-Tricalcium Phosphate}

It is a smart calcium phosphate system that effectively regulates the diffusion of tooth mineral ions to the tooth and collaborates with fluoride, thereby upgrading its performance. $^{22}$ Tricalcium phosphate (TCP) is a partially soluble precursor to hydroxyapatite and is mainly produced to coincides with fluoride in both aqueous and non-aqueous product formats. Crystalline $\beta$-tricalcium phosphate ( $\beta$-TCP), when reshaped by the combination of carboxylic acids and surfactants, yields the functionalised form of $\beta$-tricalcium phosphate. The agenda behind functionalising $\beta$-TCP was to produce barriers averting the untimely interactions of fluoride-calcium. This permits $\beta$-TCP to behave as a targeted low-dose delivery system using dentifrices or mouthwashes as vehicles. ${ }^{22}$ The $\mathrm{pH}$ changes caused by casein phosphopeptideamorphous calcium phosphate (CPP-ACP) nano complexes can distribute $\mathrm{Ca} 2+$ and P043-ions in a stabilised form. However, functionalised tricalcium phosphate (fTCP) provides unbound ions in small proportions for short periods in the mouth. ${ }^{22}$ Clinical recommendations on employing fTCP products will be premature since there is limited evidence owing to scanty in vitro studies and well-designed randomised controlled trials (RCTs).

\section{Amorphous Calcium Phosphate (ACP)}

ACP is a dual chamber fluoride toothpaste which incorporates an unstabilised calcium-phosphate system and separately delivers $\mathrm{Ca}^{2+}$ and $\mathrm{PO}_{4}{ }^{3}$ - ions in the oral cavity. ${ }^{23}$ It results in the intraoral mixing of $\mathrm{Ca}^{2+}$ and $\mathrm{PO}_{4}{ }^{3}$ - on brushing. This is then followed by a rapid deposition of ACP or amorphous calcium fluoride phosphate. These precipitated products have been found to be unsteady, so they change rapidly to a steadier form-HA or fluorhydroxyapatite. Prior to their conversion, these ions must be available temporarily for below the surface remineralisation. A single RCT in patients undergoing radiation therapy stated that ACP technology was superior to a conventional fluoride dentifrice when reducing root caries incidence. However, no significant distinction was observed in its potential to mitigate coronal caries ${ }^{24}$ Two reported limitations of unstabilised calcium phosphate system are; they encourage dental calculus deposition and liable to sequester free F-ions in the mouth rapidly. Hence, oral products employing ACP remineralisation technology have been limited to the clinical application due to sparse evidence.

\section{Casein Phosphopeptide-Amorphous Calcium Phosphate (CPP-ACP)}

Prof. Reynolds developed casein phosphopeptide-amorphous calcium phosphate at the School of Dental Science at the University of Melbourne, Australia. ${ }^{25}$ Its formulation was built on the philosophy that the enzymatic digestion of milk casein fabricated multiphosphorylated casein phosphopeptides (CPP), considerably raises solubility of the protein content of milk and also stabilises $\mathrm{Ca}^{2+}$ and $\mathrm{PO}_{4}{ }^{3-}$ ions. ${ }^{25} \mathrm{CPP}$ biomimetics 
saliva, but it exhibits a superior property of stabilising calcium than salivary proteins.

This is because of the higher content of its phosphoseryl residues. ${ }^{26} \mathrm{CPP}$ maintains calcium and phosphate ions in an amorphous and non-crystalline state. In this state, these ions can enter the tooth enamel thereby hindering demineralisation and favouring remineralisation by precipitation of these released ions on the body of incipient lesions.

Several randomised control trials revealed that CPP-ACP products have remarkably superior remineralising and anticaries effects than placebo or fluoride containing product. $27-28$

\section{Sodium Calcium Phosphosilicate (Bioactive Glass)}

Calcium sodium phosphosilicate, was initially formulated to potentiate osteoblastic regeneration. Bioactive glass first comes in contact with saliva. It then rapidly releases $\mathrm{Na}+\mathrm{Ca}^{2+}$ and $\mathrm{PO}_{4}{ }^{3}$ - ions into this aqueous oral environment. These released ions, upon interaction with saliva, form a crystalline hydroxycarbonate apatite (HCA) layer which resembles tooth material structurally and chemically. ${ }^{29}$ These released ions then transform into HCA for up to 2 weeks. Bioactive glass was initially included in a dentifrice (NovaMin) to manage dentine hypersensitivity. Several studies have stated that Bioglass dentifrices produce higher remineralisation as compared to dentifrices containing fluoride. ${ }^{30,31,32}$ Also the addition of Bioglass to fluoride dentifrices significantly increased the uptake of fluoride into artificial enamel carious lesions and showcased a synergistic effect. ${ }^{33}$ However, available evidence from various in vitro and in situ studies is limited and conflicting. ${ }^{34}$ Hence, there is a need to conduct more RCTs to prove the superior remineralising efficacy of bioactive glass.

\section{Nano-Materials}

It has been found that nanoparticles exhibit better ion releasing profiles than microparticles. ${ }^{34}$ Nano-materials have been incorporated into restorative materials as inorganic filler particles, like composites. ${ }^{35}$

\section{Calcium Fluoride Nanoparticles}

It has been stated that nanoCaF 2 enhances the collective exposure of fluoride in comparison to conventional glass ionomer cement. This can be attributed to the surface area of $\mathrm{CaF}_{2}$ nanoparticle which is 20-times more as compared to conventional glass ionomer cements. ${ }^{35}$

\section{Calcium Phosphate-Based Nano-Materials}

Nanoparticles of HAP, TCP, and ACP are the primary originating factors of releasing tooth mineral ions, and they enhance the supersaturation state of apatite crystals in cavitated lesions. ${ }^{35}$

\section{Nano-HAP}

Synthetic nano-hydroxyapatite (nHAP) is a biologically compatible and biologically active material exhibiting comparable morphological characteristics, structural form, as well as crystallinity similar to apatite crystals. ${ }^{35}$ Nanoparticles tightly adhere to the surface of enamel as well as with plaque fragments and bacterial byproducts, thereby modifying their degree of crystallinity. nHAP significantly enhances the surface area for chemical binding and enables its functioning as filler particle in order to restore microscopic enamel defects. This produces a bound biomimetic apatitic coating on the enamel surface. The mechanism of nHAP biomimetic function put forward by some researchers is that it encourages remineralisation by creating a fresh coating of artificial enamel or laying down hydroxyapatite nanoparticles in the depressions seen on enamel surface. ${ }^{36,37}$

\section{ACP Nanoparticles}

Sphere shaped molecules with a proportion of $40-100 \mathrm{~nm}$. Nanoparticles of ACP are added to composite resins, ionomer cements, and adhesives serve as sources of calcium and phosphate ions. Nano ACP that contain nanocomposites prevent decalcification at the edge of restoration-enamel junction, and produce deficiency in the minerals of enamel in comparison to conventional composites. ${ }^{37}$

\section{Polydopamine}

In aqueous solutions, dopamine's oxidative polymerisation spontaneously forms polydopamine, mimicking dopamine but exhibits a robust adhesive property to various substrates under wet conditions. ${ }^{38}$ Collagen fibers of demineralised dentine, when coated with polydopamine, showed superior remineralising potential. This indicates that the attachment of polydopamine to collagen fibre act as a fresh site for attachment of HA crystal enabling its growth.

\section{Poly (Amidoamine) Dendrimers}

Often referred to as "artificial proteins" polyamidoamine dendrimers are highly branched polymers. They can mimic the self-assembling behavior of amelogenins into hierarchical enamel crystal structures which is why they are popularly known as "amelogenin-inspired polymers" 39 . The synthetic PAMAM, when mutated with carboxylic acid groups, exhibited the organisation, orientation, and mineral phase of intact enamel, where HAP nanorods showed close parallelism to the original prisms. However, polyamidoamine dendrimers (PAMAM)-mediated enamel remineralisation is time taking and their clinical utilisation may be unreasonable unless they are potentiated.

\section{Proanthocyanidins (PA)}

Grape seed extract (GSE) contains PA is a bioflavonoid, accommodating benzene-pyran-phenolic acid molecular nucleus. ${ }^{40}$ At a ph of 7.4, it forms insoluble HAP networks in conjugation with a remineralising agent. A concentrationdependent increase in microhardness is noticed when acidtreated decalcified dentin was subjected to grape seed extracts. In a study, the collaborative impact of PA in combination with CPP-ACP on remineralisation of root caries, Epasinghe et al. observed a substantial mineralisation and rigidity in artificial root caries. ${ }^{41}$

\section{Theobromine}

Theobromine, found in cocoa (240 mg / cup) and chocolate (1.89\%), exhibits crystalline growth in the enamel, making it less susceptible to acid attack. ${ }^{42}$ Further in vitro studies also 
indicate that cocoa bean husk effectively reduces mutant streptococci and exhibits low toxicity in contrast to fluoride. Upon comparative evaluation remineralising efficacy of dentifrices containing theobromine and sodium fluoride. It was observed that the former exhibited a significantly higher mineral gain than the latter. ${ }^{43}$ More clinical studies need to be carried out to establish the safe use of theobromine.

\section{Arginine Bicarbonate}

Arginine is a partly-essential amino acid seen in salivary proteins, with calcium carbonate molecules that bond to the surface of mineral. Non-cariogenic bacteria, such as Streptococcus sanguinis, utilise arginine bicarbonate through the arginine deaminase to manufacture energy, ammonia and carbon dioxide. Arginine was first identified by Kleinberg et al. and a new dentifrice containing $1.5 \%$ arginine was developed and is commercially available (Colgate-Palmolive, New York). ${ }^{44} \mathrm{~A}$ systematic analysis done by Jialing Li et al. reported that when added to a tooth mineral compound and fluoride, arginine provided a substantial anti-cariogenic action in comparison to similar fluoride formulations alone. 45

\section{Self-Assembling Peptides}

A recent development in the enamel regeneration approach is a monomeric peptide which has a unique attraction towards calcium ions and promotes seeding for de novo HAP formation leading to remineralisation, ${ }^{46}$ P11 - 4 can cause a reversal of initial lesions on occlusal and proximal surfaces. P11 - 4 treated carious lesions showed superior aesthetics and higher radiopacity that remained stable even $6-12$ months posttreatment.

\section{Biomimetic Remineralisation}

There has been a change in understanding from reparative towards regenerative biomineralisation, wherein biologically similar tissues replace diseased dental tissues. Mature enamel's acellular property and its inability to resorb or remodel itself, unlike bone or dentine, makes regeneration challenging. ${ }^{47}$ However, demineralised dentin collagen is then backfilled with ACP nano precursor particles in fluid state which are balanced by noncollagenous proteins. These pre nucleation clumps $(\sim 1 \mathrm{~nm})$ then agglomerate into greater $(10$ - $50 \mathrm{~nm}$ ) ACP nanoparticles in fluid state, which penetrate intrafibrillar water sections of collagen fibres and undertake self-building to transform into a metastable crystalline phase. The stabilised crystals eventually combine into single apatite crystallites within the zone between the collagen molecules.

\section{Electric Field-Induced Remineralisation}

The electric field manipulates particles with the precedence of sturdy configuration and superior organisation utilising the low amperage of electrical current. Wu targeted at initial and moderate enamel lesions, re-establishing the full body of the carious lesion and improving the treated enamel's mechanical properties with no broken rods or degraded prisms. It works on the principle of iontotherapy to accentuate the movement of these remineralising ions in the profound layers of cavitated lesion thereby creating a habitat that favors restoration of the lesion. This remineralised lesion then grows imparting it with adequate hardness and mineral density. 48

\section{Xylitol}

Xylitol is a non-fermentable sugar alcohol that has shown the anti-caries effect. It decreases Streptococcus mutans (MS) levels in plaque and saliva by inhibiting their processes of energy generation of polysaccharides, ultimately resulting in a worthless cycle of energy leading cell death. ${ }^{49}$ It lessens these microorganisms' union to the surface of hard tissues and lessens production of acid. Xylitol also encourages remineralisation by enhancing the flow of saliva as chewing gum or large xylitol lozenge resulting in a superior buffering potential against an acidic environment.

\section{CONCLUSIONS}

The dawn of preservative and minimal intervention dentistry demonstrates that newer approaches for enamel remineralisation are the need of the hour, independent of fluoride remineralising systems. Non-fluoridated remineralisation systems are not dependent on variables like saliva quality and patient compliance. However, most currently available non-fluoride remineralising systems are based on improving efficacy of fluoride and reducing the possible fluoride concerns. There is a need for a biomimetic approach for regeneration of enamel in the long term which focuses on sturdy attachment of enamel apatite crystals to the tooth surface, akin to the creation of artificial enamel.

Financial or other competing interests: None.

Disclosure forms provided by the authors are available with the full text of this article at jemds.com.

\section{REFERENCES NEW}

[1] Usha C, Sathyanarayanan R. Dental caries - a complete changeover (Part I). J Conserv Dent 2009;12(2):46-54.

[2] Cochrane NJ, Cai F, Huq NL, et al. New approaches to enhanced remineralisation of tooth enamel. Journal of Dental Research 2010;89(11):1187-97.

[3] Robinson C, Shore RC, Brookes SJ, et al. The chemistry of enamel caries. Crit Rev Oral Biol Med 2000;11(4):481-95.

[4] Hemagaran G. Remineralisation of the tooth structure: the future of dentistry. Int J PharmaTech Res 2014;6(2):48793.

[5] Naveena P, Nagarathana C, Sakunthala BK. Remineralizing agent-then and now-an update. Dentistry 2014;4(9):256.

[6] Cochrane NJ, Zero DT, Reynolds EC. Remineralisation models. Advances in Dental Research 2012;24(2):129-32.

[7] Mattousch TJH, van der Veen MH, Zentner A. Caries lesions after orthodontic treatment followed by quantitative light - induced fluorescence: a 2 - year follow - up. Eur J Orthod 2007;29(3):294-8. 
[8] Dowd FJ. Saliva and dental caries. Dent Clin North Am 1999;43(4):579-97.

[9] Silverstone LM. Remineralisation of human enamel in vitro. Proc R Soc Med 1972;65(10):906-8.

[10] Benson PE, Parkin N, Dyer F, et al. Fluorides for the prevention of early tooth decay (demineralised white lesions) during fixed brace treatment. Cochrane Database Syst Rev 2013;(12):CD003809.

[11] Ball IA. The 'fluoride syndrome': occult caries? British Dental Journal 1986;160(3):75-6.

[12] Singh M, Kaur M. Fluoride alternatives: a review of the present status. Contemporary Dent Sci 2011;1:54-61.

[13] Agustsdottir H, Gudmundsdottir H, Eggertsson H, et al. Caries prevalence of permanent teeth: a national survey of children in Iceland using ICDAS. Community Dent Oral Epidemiol 2010;38(4):299-309.

[14] Birkeland JM, Ibrahim YE, Ghandour IA, et al. Severity of dental caries among 12 - year - old Sudanese children with different fluoride exposure. Clin Oral Investig 2005;9(1):46-51.

[15] Duggal MS, van Loveren C. Dental considerations for dietary counselling. International Dental Journal 2001;51(6 Suppl 1):408-12.

[16] Grandjean P, Landrigan PJ. Neurobehavioural effects of developmental toxicity. The Lancet Neurology 2014;13(3):330-8.

[17] McGrady MG, Ellwood RP, Maguire A, et al. The association between social deprivation and the prevalence and severity of dental caries and fluorosis in populations with and without water fluoridation. BMC Public Health 2012;12:1122.

[18] Pendrys DG. Risk of enamel fluorosis in nonfluoridated and optimally fluoridated populations: considerations for the dental professional. The Journal of the American Dental Association 2000;131(6):746-55.

[19] Philip N. State of the art enamel remineralisation systems: the next frontier in caries management. Caries Res 2019;53(3):284-95.

[20] Kalra DD, Kalra RD, Kini PV, et al. Nonfluoride remineralisation: an evidence - based review of contemporary technologies. Journal of Dental and Allied Sciences 2014;3(1):24-33.

[21] Exterkate RAM, Damen JJ, ten Cate JM. A single-section model for enamel de- and remineralization studies. 1 . The effects of different $\mathrm{Ca} / \mathrm{P}$ ratios in remineralisation solutions. Journal of Dental Research 1993;72(12):1599603.

[22] Karlinsey RL, Mackey AC, Walker ER, et al. Surfactant modified beta - TCP: structure, properties and in vitro remineralisation of subsurface enamel lesions. J Mater Sci Mater Med 2010;21(7):2009-20.

[23] Tung MS, Eichmiller FC. Amorphous calcium phosphates for tooth mineralization. Compendium Contin Educ Dent 2004;25(9 Suppl 1):9-13.

[24] Papas A, Russell D, Singh M, et al. Caries clinical trial of a remineralising toothpaste in radiation patients. Gerodontology 2008;25(2):76-88.

[25] Reynolds EC. The prevention of sub - surface demineralisation of bovine enamel and change in plaque composition by casein in an intra - oral model. J Dent Res 1987;66(6):1120-7.
[26] Reynolds EC. Casein phosphopeptide - amorphous calcium phosphate: the scientific evidence. Adv Dent Res 2009;21(1):25-9.

[27] Bailey DL, Adams GG, Tsao CE, et al. Regression of post orthodontic lesions by a remineralizing cream. J Dent Res 2009;88(12):1148-53.

[28] Guclu ZA, Alacam A, Coleman NJ. A 12 week assessment of the treatment of white spot lesions with CPP-ACP paste and / or fluoride varnish. Biomed Research International 2016;2016:8357621.

[29] Sitthisettapong T, Doi T, Nishida Y, et al. Effect of CPP ACP paste on enamel carious lesion of primary upper anterior teeth assessed by quantitative light induced fluorescence: a one - year clinical trial. Caries Res 2015;49(4):434-41.

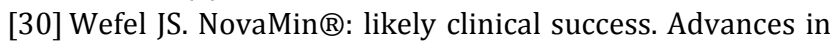
Dental Research 2009;21(1):40-3.

[31] Alaudin SS, Fontana M. Evaluation of Novamin ${ }^{\circledR}$ as an adjunct to fluoride for caries lesion remineralisation. NovaMin $®$ Research Report 2006.

[32] Golpayegani MV, Sohrabi A, Biria M, et al. Remineralisation effect of topical NovaMin versus sodium fluoride $(1.1 \%)$ on caries - like lesions in permanent teeth. Journal of Dentistry (Tehran, Iran) 2012;9(1):6875.

[33] Stone AH, Schemehorn BR, Burwell AK. Enhanced enamel fluoride uptake from NovaMin $\AA$ - Containing fluoride dentifrices. J Dent Res 2008;87(Spec Iss B):625-8.

[34] Wang Y, Mei L, Gong L, et al. Remineralisation of early enamel caries lesions using different bioactive elements containing toothpastes: an in vitro study. Technol Health Care 2016;24(5):701-11.

[35] Zhang X, Deng X, et al. Remineralising nano materials for minimally invasive dentristry. Chapter Nanotechnology in endodontics: current and potential clinical application. Switzerland: Springer International Publishing 2015: p. 173-93.

[36] Hanning M, Hanning C. Nanomaterials in preventive dentistry. Nat Nanotechnol 2010;5(8):565-9.

[37] Pepla E, Besharat LK, Palaia G, et al. Nano - hydroxyapatite and its applications in preventive, restorative and regenerative dentistry: a review of literature. Ann Stomatol (Roma) 2014;5(3):108-14.

[38] Zhou YZ, Cao Y, Liu W, et al. Polydopamine - induced tooth remineralisation. ACS Appl Mater Interfaces 2012;4(12):6901-10.

[39] Wu D, Yang J, Li J, et al. Hydroxyapatite - anchored dendrimer for in situ remineralisation of human tooth enamel. Biomaterials 2013;34(21):5036-47.

[40] Benjamin S, Sharma R, Thomas SS, et al. Grape seed extract as a potential remineralising agent: a comparative in vitro study. J Contemp Dent Pract 2012;13(4):425-30.

[41] Epasinghe DJ, Yiu C, Burrow MF. Synergistic effect of proanthocyanidin and CPP - ACFP on remineralisation of artificial root caries. Aust Dent J 2015;60(4):463-70.

[42] Nakamoto T, Falster AU, Simmons Jr WB. Theobromine: a safe and effective alternative for fluoride in dentifrices. Journal of Caffeine Research 2016;6(1):1-9.

[43] Amaechi BT, Porteous N, Ramalingam K, et al. Remineralisation of artificial enamel lesions by theobromine. Caries Res 2013;47(5):399-405. 
[44] Wijeyeweera RL, Kleinberg I. Arginolytic and ureolytic activities of pure cultures of human oral bacteria and their effects on the $\mathrm{pH}$ response of salivary sediment and dental plaque in vitro. Arch Oral Biol 1989;34(1):43-53.

[45] Jialing Li, Huang Z, Mei L, et al. Anti-caries effect of arginine-containing formulations in vivo: a systematic review and meta - analysis. Caries Res 2015;49(6):606-17.

[46] Kind L, Stevanovic S, Wuttig S, et al. Biomimetic remineralisation of carious lesions by self - assembling peptide. J Dent Res 2017;96(7):790-7.
[47] Schlee M, Rathe F, Huck T, et al. Klinischer effekt biomimetischer mineralisation bei approximalkaries. Stomatologie 2014;111:175-81.

[48] Wu XT, Mei ML, Li QL, et al. A direct electric field-aided biomimetic mineralization system for inducing the remineralisation of dentin collagen matrix. Materials (Basel) 2015;8(11):7889-99.

[49] Trahan L, Néron S, Bareil M. Intracellular xylitol-phosphate hydrolysis and efflux of xylitol in Streptococcus sobrinus. Oral Microbiology and Immunology 1991;6(1):41-50. 